\title{
Reviewing the Internal Obstacles to Women's Equal Rights Movements
}

\author{
Xiang $\mathrm{Li}^{1, \mathrm{a},{ }^{*}, \dagger}$, Youtian $\mathrm{Li}^{2, \mathrm{~b},{ }^{*}, \dagger}$, Jintong Que ${ }^{3, \mathrm{c},{ }^{*}, \dagger}$, Jiajing Wang ${ }^{4, \mathrm{~d}, *, \dagger}$ \\ ${ }^{1}$ Ningbo University, Ningbo, Zhejiang, 315211, China \\ ${ }^{2}$ University of Wisconsin Madison, Madison, 53715, USA \\ ${ }^{3}$ University of Minnesota, Minneapolis, Minnesota, 55455, USA \\ ${ }^{4}$ Guangxi University for Nationalities, Nanning, Guangxi, 530000, China \\ *Corresponding author.Email: ${ }^{*} 186003406 @ n b u . e d u . c n ;{ }^{b}$ li775wisc@edu \\ cque00003@umn.edu; ${ }^{d} 118233020349 @ s t u . g x u n . e d u . c n$. \\ These authors contributed equally.
}

\begin{abstract}
The main objective of feminism movements is to make societal changes for women's rights achieving gender neutrality, improving society into a better place to live for women while they receive numerous challenges. This paper reviews the previous various gender cases and feminism movements worldwide to specifically point out those internal oppression factors toward equal rights movements that come from the group of women. By dividing the factors into the category of consciousness and unconscious one, we find out 1) unconscious factors include women's lack of female consciousness and the limitations in the feminist movements; 2) conscious factors consist of four parts: nonfeasance which refers to the failure to perform the law, meaningless action, individuals take advantage of equal right movements and harmful behavior. These findings imply that current feminism movements encounter obstacles that are not only from the traditional male-dominant social structures but also internal suppression. If a source of strategy could be established according to this analysis for future directions, then the efforts of feminism movements can move into a better stage.
\end{abstract}

Keywords: Equal Right Movement, Female Consciousness, Gender Discrimination, Nonfeasance.

\section{INTRODUCTION}

This article aims to clarify a number of internal factors which hinder the overall application of the feminism movements throughout history. White women from the middle class advocate, the first feminism movement, to stop legal distinctions for women's suffrage and political equality. As the wave of the second feminism movement deals with the inequalities of laws regarding women, it does not include the group of women of color and cultural equality. The third- and fourth-wave of feminism movements then take issues of race, class, sexual orientation, and other factors of identity into account. When the recent progress on this topic focuses on external factors in the feminism movement, it may neglect those potential obstacles from women themselves, which probably lead to some inefficient solutions. Based on those previous studies, we emphasize our research on the conscious factors and unconscious factors that cause women to be repulsive to equal rights movements.

\section{UNCONSCIOUS FACTORS}

The unconscious factor means that some women's actions or thoughts hinder the development of affirmative action unconsciously. This part will be divided into two categories for discussion: the lack of women consciousness of women, and the other is the limitations of liberal feminism and radical feminism.

\subsection{Women's Lack of Consciousness}

When some women face the fact of social gender injustice, they cannot well realize that they are placed in an unfair position. This will be regarded as "Women's lack of consciousness".

On this point, the concrete manifestation can be segmented into two stages. In the early stage, women will have self-objectification, regard themselves as the appendage of men, and actively curry favor with the 
social rules of male power. This can be proved by a historical example that happened between 1905 and 1914

The militant suffrage movement of the Women's Social and Political Union means that some British women who could be called suffragettes established the union to achieve the goal of giving women more voting rights in public elections in that period. During that time, Humphry Ward, the famous British women writer, established the Women's National Anti-Suffrage League in 1908. It was a specialized anti-suffragist coalition whose main goals were to oppose women's participation in the national parliament, to support women's participation in local councils or those private areas such as their own family [1]. The main argument of the AntiSuffragette League was that women's natural place was in the private sphere, and the savage public sphere was that of men. The fact that women themselves set up oppositional organizations was enough to show that some women, rather than fighting desperately, were more willing to recognize the fixed traditional status and division of labor given to them by society. It can be seen that sometimes women are not clear about their social roles and status due to the profound influence of society and history, since this kind of behavior is not so much a rare phenomenon as a common one.

Another typical example is the appearance anxiety and figure anxiety of women in modern society, which is also the performance of self-objectification. Studies have shown that self-objectification and figure mass index significantly positively affect women college students' depression [2]. With the increase of individual figure mass index, the predictive power of self-objectification on depression tends to increase [2].

When it comes to the next stage, women will think about the patriarchal society and impose unfair rules on other women to require them to adapt to the patriarchal society. It is evidenced in the contradiction between mother-in-law and daughter-in-law in China. Some of the mothers-in-law, as women, have gradually lost their thinking under the pressure of society. In the traditional Chinese family, the corrupt patriarchal social ideas, such as inheriting the family line and primogeniture, still profoundly influence the members. If a woman wants survival status in the family, she must give birth to at least a son. Usually, this harsh and unreasonable request will be enforced by a mother-in-law who was once a victim. This point has been reflected in many Chinese literary works, such as the Peacock Flying Southeast in the Eastern Han Dynasty and the Field of Life and Death by Xiao Hong - one of the female writers in China.

The lack of women's consciousness usually occurs for two reasons. One is internal to women. In the patriarchal society, women are less educated, lacking a sense of independence. Men use this to constantly hypnotize the output of women's opinions. The other is benevolent gender bias in patriarchal societies, a bias that is hard to detect. The benign gender bias in the conflicted gender theory includes paternalism, complementary gender differentiation, and heterosexual intimacy [3]. The essence of this is that men love women subjectively but restrict women to the traditional gender role. This bias is not easy to detect but easily accepted by women, for example, who are quite willing to allow men to do more and more difficult roles in the workplace. But it turns out that well-intentioned gender bias is just an acceptable way to rationalize sexism.

\subsection{The Limitations of Liberal Feminism and Radical Feminism}

In the process of exploring the feminist movement, due to the lack of scientific theories and rationalization approaches, women have brought negative effects or even objective obstacles to the equal rights movement while fighting for their own rights. Liberal feminism and radical feminism will be the main objects of discussion in the following paragraphs, and other schools will not be considered for the time being.

The basic idea of liberal feminism is that women and men should enjoy almost identical political and civil rights, and radical feminism believes that the oppression of women from the patriarchal society is the basis of all oppression. They hope to destroy it and find a new balance between two genders through a thorough revolution.

Although each school has different goals and ways of the feminist movement, this incomplete exploration in the development process mainly comes from the theoretical deficiency of the feminist movement and the development model of feminism. In terms of theoretical construction, women's research on feminist theory in the process of the feminist movement lacks in systematisms, highly theoretical and rigorous. This has to do with the biology of women themselves and the fact that the feminist movement has yet to succeed. Women are still fighting for their own rights and cannot rationally and objectively sort out theories and form a system. Then, the deviation of women's understanding of "gender equity". It is a concept that has always existed in human activities but has been ignored, divided into the equity of value. In the process of liberation, that of rights leads to the narrow liberation of women's rights, or excessive liberation leads to women becoming bullies in the sense of society. This is reflected in the development mode as the feminist movement broke out continuously with the change of times in different periods, showing a repeated trend from depression to intense and then to depression. This dynamic practice process reflects women's continuous explorations of feminism and shows women's repeated misunderstandings of the concept of "equity" in this process. 
The distinguishing feature of liberal feminism is that they demand complete equality with men. This school of theory denies the objective differences between the sexes and equates women's rights with men's. In essence, it has not escaped from the confinement of patriarchal culture. Therefore, liberal feminism did not get the imagined fair treatment but caused a lot of trouble. In 1923, the U.S. Congress proposed the Equal Rights Amendment, which proposed to deny women care and protection [4]. The proposal would result in the non-existence of some protections for women, putting women in an even more unfavorable position since there must be biological differences between the sexes. Not only that, but the behavior of liberal feminism also creates social problems beyond the consideration of the feminist movement. A constitutional amendment proposed in 2000 in France required that candidates have equal numbers of men and women on their lists, with fines imposed on violators [5]. This is not only inconsistent with feminist ideology but also disrupts the fairness of social competition. Forced gender equity is fundamentally another form of bullying.

Radical feminism has exerted more negative influences on feminism and the rights movement than any other school. During the radical political participation movement of the British Union, the unrestrained violence of the Union gradually led to the opposition of public opinion and public opinion, and even people held fierce opposition to their behavior. For this phenomenon, many newspapers and women scholars' statements can testify: Ray Strachey argued in The Cause that the actions of the allies were irrational and barbaric [6]; The Manchester Guardian, on 2 March 1912, commented on the Alliance's actions: "These mad women have misled the noble and serious women's suffrage movement, and rather than advancing it, they have set it back." [7]. Even members of the coalition question the effectiveness of the violence. Pethick Lawrence, for example, argues that the destruction of private property has created a new backlash [8]. Nowadays, with the development of the Internet, some radical feminists have made many extreme comments on the Internet without any scruples, which has left people a wrong impression on feminism, believing that feminists are violent, irrational, and tyrannical. It hinders the advancement of the feminist movement and undermines the purity of feminism, improving the progress of feminism.

\section{CONSCIOUS FACTORS}

As it has been mentioned that women sometimes unintentionally hinder the development of the equal rights movement, intentional factors cannot be ignored as well. Under this circumstance, intentional factors usually mean that some women firstly have the consciousness of feminism. Still, they intentionally do not pursue equality, even repel and hinder others from speaking or pursuing equality.
Among those women who ignore the development of the equal rights movement, some did nothing to support the equal rights movement. When this kind of behavior expands, it will cause the affirmative movement and even the stagnation of social development. Some of them probably believe that there is nothing they can do, or nobody is leading them. They have relative apathetic thought especially some of them have been oppressed for many years. Others believe that they can take advantage of gender inequality to acquire their interest.

In addition, some people take action to stop discrimination. However, some of them have behavior that would hinder the development of equality on purpose. At the same time, others could do something not on purpose but also harm the development of the equal rights movements.

\subsection{Nonfeasance}

Since achieving equality is people's common idea, some people know their responsibility but choose to do nothing. We define those people as nonfeasance people. For people that already feel numb to injustice, we search several cases to make this concept clearer. Although many policies have been introduced to protect women's rights and eliminate gender discrimination, it is no doubt that in society, there still are various kinds of gender discrimination, especially in the workplace. In China, a few women choose to resign when they find that they are pregnant and return to the workplace when their children are about one year old. This results in the fact that employers must take their lack of experience into account when comparing with other peers who do not have kids and continue working. Also, the employers will be doubtful about these women's indulgence in work. There is a bias in the workplace that if women pay much attention to their families, people will think that women cannot fully devote themselves to work. Perhaps most women will argue against this kind of bias. When more and more companies reject women for the same reason, they will be desperate to eliminate bias. Gradually, they become apathetic.

\subsection{Meaningless actions}

After being oppressed for so many years, some women start to believe that eliminating inequality is helpless. Under this circumstance, some start making irresponsible and carping comments for those who fight for the equal rights movement. At the same time, some people start to generate some opportunistic ideas. They believe they can make a profit on their own when everyone is fighting for equal rights. Recently on TikTok, there are many bloggers recording videos to claim that women can be defined as successful only when they can be totally dominated. According to Luo, some blogger makes up some plot to sale their counterfeit products. [9] 
They are usually a bunch of people with an extreme comment trying to draw public attention. In China, with the development of modernization, the traditional gender concept has transformed, transferring to the modern gender concept -- gender equality. More and more people gave up the idea that men are superior to women. However, Yang argues that the development of the economy, the popularization of education, and the transmission of information lead to the return of traditional consciousness instead of making gender concepts more equal [10]. For example, a saying goes, "A woman prefers to marry well than to do well." In China, women's gender concept is deeply rooted in the Chinese system, culture, and tradition. The three obedience's and the four virtues in the traditional patriarchal culture make it difficult for women to attain their social-economic status by doing a good job. It results in the fact that having a good marriage becomes the primary approach to gaining good status in society and women tend to depend on men.

$\mathrm{Li}$ argues that since the establishment of the People's Republic of China, the traditional patriarchal culture has been severely criticized during large-scale socialist transformation and Women's Liberation [11]. Women became more and more independent and could attain social-economic status by themselves. In the meantime, with the deepening of reform, the development of the economy, and society's opening, women are exposed to tremendous pressures in the workplace. Employers tend to hire men instead of women because they take women's maternity leave into account. Most women in the workplace are married, and they will get pregnant soon. Recently, the three children policy was announced on 31 May 2021 by the Chinese Communist Party. [12]It is a part of the plan of family planning policy. It mainly claims that the number of children a family wants to birth to depends on the law. Women are treated like they are born for birth, which means disrespect for women. Also, this policy undoubtful makes women have harder life in their workplace. Discrimination against women will increase. During maternity leave, there is nobody else who can replace her, and the number of employees who bring benefits to the company will become less. The great employment pressure women face in the workplace leads to the fact that women are less likely to do good jobs than men. Then, Li argues that having good marriages traditionally becomes a "rational" choice for women, which results in the return of traditional consciousness [11].

Feminism aims to "save" those women who are seriously influenced by patriarchy and try to change their lives and attitudes. Nevertheless, for those who have been oppressed by patriarchy, this kind of change can be painful. These women live in an occlusive environment with single values and seriously traditional values. In a patriarchal society, male chauvinists sanctify the family and fertility. Family and fertility have been the whole ideal and pursuit of these women, which has dramatically influenced the feminist movements. Telling them that family is not a woman's whole life means destroying their spiritual prop. Moreover, the collapse of faith is painful for some of them, which means that they are told that the efforts they have made before are all useless. In this way, most women will deny the fact instinctively. Furthermore, these women become the opponents of feminists. Meanwhile, the people feminists want to save are strictly these women. However, this kind of situation makes some feminists lose their hope and think that all the solutions they come up with are useless. Furthermore, even some feminists want to give up these women. Instead of saving them, they tend to fight against these women. Therefore, feminists should treat women, especially women against feminism, equally and respectfully, admit their pain, and express their own opinions, life, and values. They should communicate with these women and guide them to help them live a better life and promote social progress.

\subsection{Taking advantage of equal rights movements}

Feminist movements aim to eliminate gender discrimination and gender inequality and raise the position of women. Nowadays, some people distort the connotation of feminism. They tend to talk about the misbehavior in games, ambiguity of proverbs, and even fabricate excuses for those women who have done something terrible. The worst part is that they even criticize the government without any reasonable reasons. Many women are oppressed by labor discrimination, education discrimination, and other kinds of discrimination. Those so-called feminists do not care about these things. They tend to understand. It is these socalled feminists that make other people have a terrible impression on feminism, which has hampered feminist movements to some extent.

\subsection{Harmful Behaviors}

In forming domestic feminist ideology, due to different opinions and different ways of action within feminist groups, consensus cannot be formed within the feminist group. Meanwhile, in society, much criticism of feminism has always appeared. Some people say that feminism pays more attention to words instead of actions. Moreover, Huang argues that some people argue that feminism pays more attention to rights and almost ignores obligation. More and more people in China have become opponents of feminists [13]. During the argumentation between feminists and anti-demises, some extreme opinions take advantage of this opportunity. They want to establish an extreme feminist society, which has formed a threat to feminism because feminism lacks some relevant theories. This is the critical period for feminism because it can be easily deconstructed. 


\section{CONCLUSION}

We have presented the internal factors which block the triumph in supporting women in patriarchal societies to change and improving their living circumstances. By identifying women's conscious and unconscious factors, we demonstrate that these diverse factors relatively lead to the current controversial situation of feminism movements. This analysis could enable an innovative approach and response to existing malicious opinions and actions against equal rights movements, along with achieving their original and rightful status. In the future, policymakers and feminists may need to change their assumptions on how feminism movements should move forward. With more mature guidance, the feminism movements will have the ability to create a platform of self-respect and admiration for women when they are provided with equal social status in society.

\section{REFERENCES}

[1] Wang, Z. (2008). Radical Feminism: The militant suffrage movement of the women's social and political union. Shang Hai, SH: Sanlian Bookstore.

[2] Liu, Y.N., \& Wang, C. (2021). The relationship between self-objectification and depression of women college students: The moderating effect of body mass index. Journal of Tonghua Normal University (01),79-84. DOI :10.13877/j.cnki.cn221284.2021.01.012.

[3] P. Glick, S. T. Fiske. (1996). The ambivalent sexism inventory: Differentiating hostile and benevolent sexism. Journal of Personality and Social Psychology, 70(3):491-512.

[4] Luan, L.C. (2011). The Equal Rights Amendment and its Failure in American Constitutional Amending History. (M.A. thesis. East China University of Political Science and Law)

[5] Cao, D.X., \& Huang, H. (2018). Antoinette Fogg and the French Equal Movement. Dushu, (10), 6068 .

[6] R. Strachey, The Cause: A Short History of the Women's Movement in Great Britain, London: G. Bell and Sons, 1978.

[7] Johndclare.net. 2021. Did the Suffragettes help women's suffrage?. [online] Available at: http://www.johndclare.net/Women2_DidSuffragett esHelp.htm [Accessed 29 June 2021].

[8] Johndclare.net. 2021. Did the Suffragettes help women's suffrage?. [online] Available at: http://www.johndclare.net/Women2_DidSuffragett esHelp.htm [Accessed 29 June 2021].
[9] Luo, Y. (2021,apr 29) Intimate relationship live broadcast routines revealed: writing scripts, acting hype, selling miserable goods. China economy website.

http://m.ce.cn/yw/gd/202104/29/t20210429_36521 809.shtml.

[10] Xu, Q. (2016). The Trends, Sources and Heterogeneity of Chinese Gender Concepts: A Case Study of Two Indicator: "Men Focus on Outsiders and Women Focus on Outsiders" and "Doing well is not as good as marrying well". Journal of Chinese Women's Studies, 3, 33-43.

[11] Li, Y. J.,\&Wang, J.(2021). Social Mobility and Traditional Gender Consciousness: taking "A woman prefers to marry well than to do well" as an example. Sociological Review of China, 9(2), 92114.

[12] Reuters. (2021, May 31). China announces threechild policy, in major policy shift. India Today. Htt zps://www.indiatoday.in/world/story/china-threechild-policy-changed-1808997-2021-05-31.

[13] Huang, C. X. (2019). The Awakening and Origin of Feminism. People's Tribune, 2, 33-75. 